\title{
Participación de Rhipicephalus sanguineus en la transmisión de Anaplasma platys en caninos
}

\author{
Rhipicephalus sanguineus as biological vector of Anaplasma platys in dogs \\ Juan Uzcategui ${ }^{1}$, María Forlano ${ }^{1,3}$, Franklin Mujica ${ }^{1}$, Nelson Orellana ${ }^{2}$
}

\section{Resumen}

El objetivo del estudio fue determinar la participación de la garrapata Rhipicephalus sanguineus en la transmisión de Anaplasma platys en caninos. Se inoculó un canino con una cepa de $A$. platys y una vez que desarrolló parasitemia confirmada por frotis y por $\mathrm{PCR}$, se le infestó con ninfas y adultos de $R$. sanguineus. Se colectaron las garrapatas ingurgitadas, se colectó el intestino y la glándula salival de las garrapatas alimentadas en el canino inoculado y se realizó un PCR. No se amplificó ADN de $A$. platys en el macerado de ninfas, en adultos pos-muda sin alimentar, o en adultos alimentados del canino inoculado experimentalmente. Los resultados indican que la $R$. sanguineus no participa en la transmisión de $A$. platys.

Palabras clave: Rhipicephalus sanguineus; vector; Anaplasma platys; transmisión

\section{AbSTRACT}

The aim of this study was to determine the involvement of the tick Rhipicephalus sanguineus in the transmission of Anaplasma platys in canines. A canine was inoculated with a strain of $A$. platys and once it developed parasitemia confirmed by smears and PCR, it was infested with nymphs and adults of $R$. sanguineus. The engorged ticks were collected, the intestine and the salivary gland were collected from the ticks fed in the inoculated canine and a PCR was performed. DNA from $A$. platys was not amplified in the

\footnotetext{
${ }^{1}$ Departamento de Salud Pública, Decanato de Ciencias Veterinarias, Universidad Centroccidental «Lisandro Alvarado» (UCLA), Barquisimeto, estado Lara, Venezuela

${ }^{2}$ Departamento de Medicina y Cirugía, Decanato de Ciencias Veterinarias, Universidad Centroccidental «Lisandro Alvarado»(UCLA), Barquisimeto, estado Lara, Venezuela

${ }^{3}$ E-mail: mforlano@ucla.edu.ve
}

Recibido: 28 de agosto de 2018

Aceptado para publicación: 29 de mayo de 2019 
macerated nymphs, in post-molded adults without feeding, or in adults fed from the experimentally inoculated canine. The results indicate that $R$. sanguineus does not participate in the transmission of $A$. platys.

Key words: Rhipicephalus sanguineus; vector; Anaplasma platys; transmission

\section{INTRODUCCIÓN}

La anaplasmosis canina es causada por dos agentes bacterianos gramnegativos, intracelulares obligados denominados Anaplasma phagocytophilum y Anaplasma platys. Ambos patógenos están clasificados en el orden Rickettsiales, que incluye a miembros de los géneros Ehrlichia, Anaplasma, Cowdria, Wolbachia y Neorickettsia. A. platys presenta morfología altamente variable, desde formas cocoides o cocobacilares a formas moldeadas o contorneadas. Presenta metabolismo anaeróbico y se reproduce por fisión binaria dentro de una vesícula endosómica, y parasita las plaquetas (Rikihisa, 1991, 1996; Dumler et al., 2001).

La enfermedad tiene un periodo de incubación de 8-15 días. El contaje inicial de plaquetas aumenta para luego caer a $20000 /$ $\mathrm{ml}$ o menos y el microorganismo puede no ser visible en el frotis de la capa blanca. Posteriormente, el patógeno desaparece de la circulación y el contaje plaquetario se incrementa rápidamente en un lapso de 3-4 días. Episodios donde coincide la disminución del contaje plaquetario y parasitemia se presentan a intervalos regulares de 1-2 semanas. La naturaleza cíclica de la parasitemia y trombocitopenia disminuyen con el tiempo presentando trombocitopenias que resuelven lentamente asociadas con la aparición esporádica del parásito en la sangre (Harvey et al., 1978; Arun et al., 2017). Los principales síntomas de la enfermedad son fiebre, decaimiento, pérdida de peso, petequias en las mucosas, lesiones hemorrágicas cutáneas y hemorragias fatales en casos graves (Dumler et al., 2001).
En Venezuela, Arraga et al. (1997) reportaron la presencia de Ehrlichia platys (Anaplasma platys) describiendo la posible transmisión natural a través de Rhipicephalus sanguineus. Asimismo se ha reportado la presencia de Ehrlichia (Anaplasma) platys $(16 \%)$ y se ha identificado a $R$. sanguineus en el $81.3 \%$ de los animales muestreados en el Edo. Falcón (Pérezy Rey-Valeirón, 2003).

Las vías de transmisión de $A$. platys pueden ser a través de vectores, de forma iatrogénica y recientemente se ha evidenciado como posible la vía de transmisión transparentaria (Latrofa et al., 2016). Algunos investigadores señalan que $R$. sanguineus posiblemente no sea el transmisor de $A$. platys (Simpson et al., 1991; Huang et al., 2005), mientras que otros lo refieren como el principal sospechoso de la transmisión de la enfermedad (Woody y Hoskins, 1991; Harrus et al., 1997; Brown et al., 2001; Dumler et al., 2001). Por otra parte, diversos estudios moleculares reportan la presencia de ADN de $A$. platys en $R$. sanguineus (Inokuma et al., 2000; Sanogo et al., 2003; Latrofa et al., 2016), indicando que este ixodido podría estar involucrado en la transmisión de la enfermedad en los caninos. Es así que el objetivo de este estudio fue determinar la participación de la garrapata Rhipicephalus sanguineus en la transmisión de Anaplasma platys en caninos para clarificar la participación de este vector en la trasmisión de esta rickettsia.

En la actualidad se ha determinado la existencia del complejo Rhipicephalus sanguineus sensu lato, conformada por al menos dos linajes con distinta distribución biogeográfica y posiblemente distinta competencia vectorial (Moraes-Filho et al., 2011); 
sin embargo, no está determinado filogenéticamente el linaje de esta especie que se encuentra circulando en Venezuela.

\section{Materiales y Métodos}

\section{Colonia de $R$. sanguineus}

La población de $R$. sanguineus se obtuvo a partir de teleoginas recolectadas de un canino negativo a $A$. platys. Las colonias obtenidas fueron alimentadas en conejos Nueva Zelanda en la Unidad de Investigación Parasitología Veterinaria (UNIPARVET) del Decanato de Ciencias Veterinarias (DCV) de la Universidad Centroccidental «Lisandro Alvrado» (UCLA). Se siguió el siguiente protocolo:

- Los huevos de las teleoginas fueron agrupados en cantidades de $100 \mathrm{mg}$ y colocados en jeringas plásticas, que fueron colocadas dentro de una cámara climatizada donde se mantuvo la humedad mediante la colocación de una solución hipersaturada de nitrato de potasio $\left(\mathrm{KNO}_{3}\right)$ en una placa Petri (Referencia). La humedad promedio fue de $79.77 \pm$ $2.48 \%$ y la temperatura de $27.06 \pm$ $1.3^{\circ} \mathrm{C}$.

- Las larvas fueron colocadas sobre las orejas de un conejo (300 larvas/oreja). Se emplearon orejeras de tela pegadas a la base de las orejas con pasta Unna's (Neitz et al., 1971) para para evitar que migren a otras zonas del cuerpo.

- Las larvas que se desprendían de forma natural fueron recolectadas en jeringas de plástico en grupos de 100 y colocadas hasta la muda a ninfas en la cámara climatizada bajo las condiciones descritas anteriormente.

- Algunas ninfas fueron colocadas nuevamente sobre un conejo, de la misma forma que se procedió para las larvas, y una vez desprendidas de forma natural fueron recolectadas, contadas en número de 50 y colocadas en jeringas de plás- tico en la cámara climatizada como se indicó anteriormente para su muda a adultas.

\section{Inoculación Experimental del Canino}

Se utilizó un canino hembra mestizo de siete meses, mantenido bajo las normas higiénicas sanitarias establecidas y alimentado a base de alimento concentrado. El canino fue esplenectomizado dos meses antes de la inoculación, según la técnica descrita por Fossum (1999), con el fin de lograr un rápido grado de parasitemia. Para descartar la presencia de $A$. platys previo a la inoculación se realizó un análisis de frotis sanguíneo, frotis de capa blanca y PCR.

La cepa de $A$. platys utilizada fue donada por la Dra. Omaira Parra, docente del Hospital Universitario de la Universidad del Zulia. La inoculación se realizó a través de la vena cefálica con $2 \mathrm{ml}$ de criopreservado de concentrado plaquetario con $80 \%$ de parasitemia. Se mantuvo un control diario de temperatura, tiempo de perfusión capilar, palpación de ganglios linfáticos, coloración de mucosas, micción y defecación. Se realizaron frotis diarios y control de hematocrito a través de una muestra de sangre colectada de la safena externa o de la vena cefálica. Los frotis fueron teñidos con métodos de coloración rápida (Hemacolor $\left.{ }^{\circledR}\right)$. El cálculo de la parasitemia se realizó mediante el contaje de tantos campos como fueran necesarios para contar 1000 plaquetas.

Una vez establecida la parasitemia se procedió a la infestación con garrapatas. Se colocaron en el canino 300 ninfas y 70 adultos de $R$. sanguineus sin alimentar, con aproximadamente 15 días de muda. Las garrapatas fueron colocadas en las orejas, según la técnica empleada por Sartor (1994), utilizando orejeras adaptadas al canino y fijadas en la base de las orejas mediante la pasta Unna's (Neitz et al., 1971) (Figura 1a). Para evitar la retirada de las orejeras fue colocado un collar isabelino ajustado con correa. Las garrapatas comenzaron a desprenderse en 


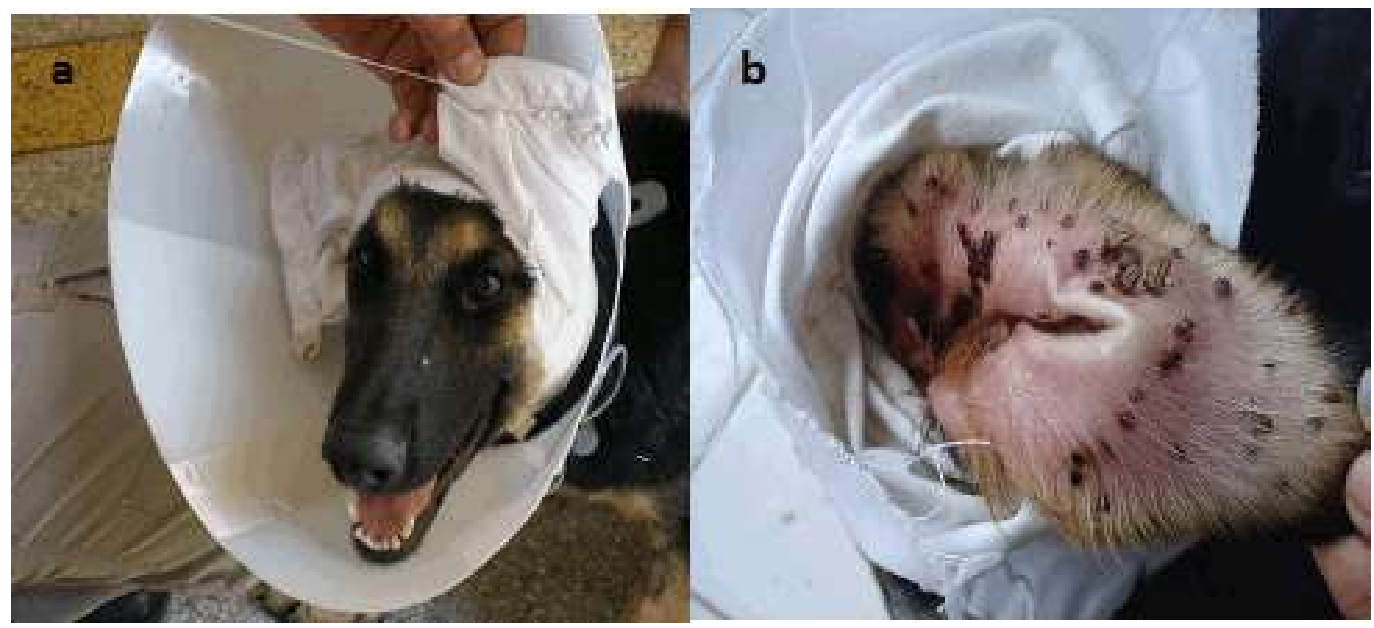

Figura 1. Infestación experimental de Rhipicephalus sanguineus en canino inoculado con Anaplasma platys. a) orejeras para evitar que las garrapatas migren a otras partes del cuerpo; b) $R$. sanguineus alimentándose

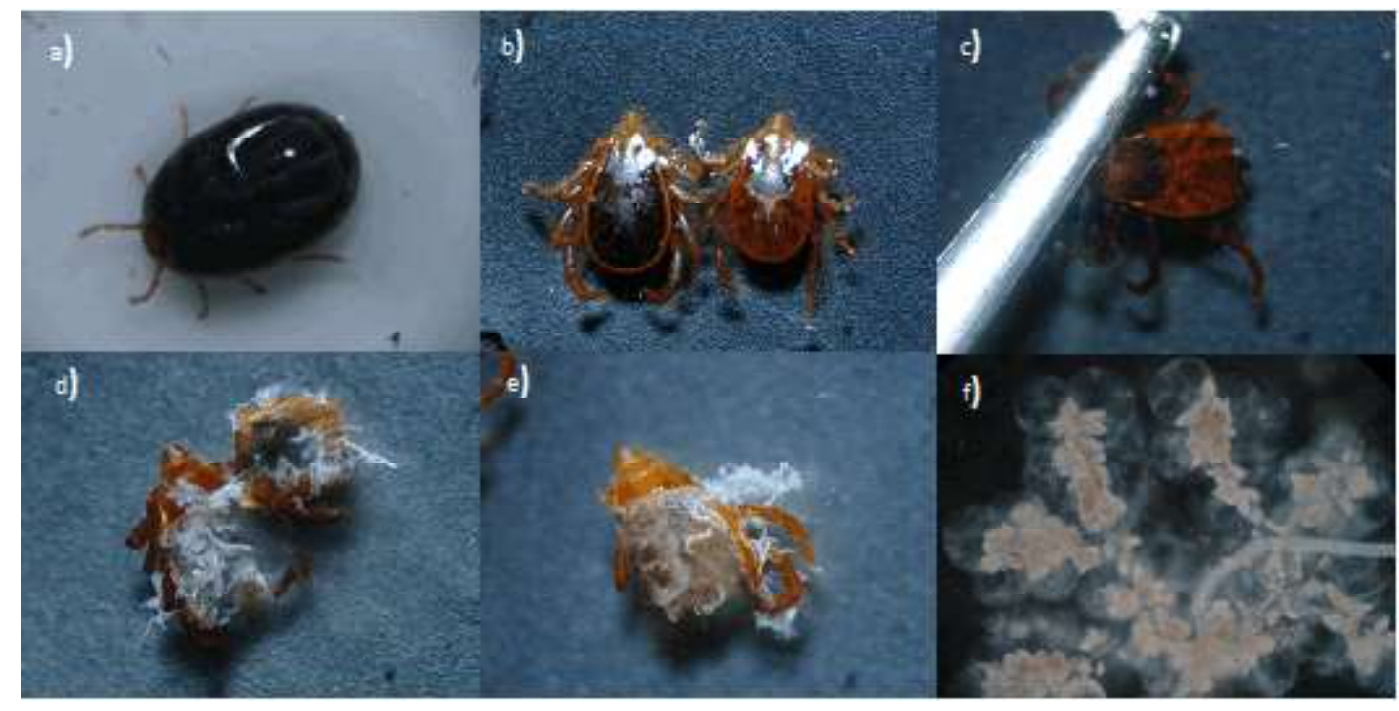

Figura 2. Secuencia de disección de la glándula salival de ninfa y adultos de $R$. sanguineus. a) ninfa de $R$. sanguineus; b) macho y hembra de $R$. sanguineus; c) sujeción de la hembra; d) y e) disección de la glándula salival de adultos; f) glándula salival de $R$. sanguineus (200X) 
forma natural a los 8 días de la inoculación con $A$. platys y fueron usadas para la extracción de ADN (Figura 1b).

\section{Sangre del Canino Infectado}

Se tomaron muestras de sangre periférica antes y después de la inoculación por punción de la vena cefálica utilizando EDTA como anticoagulante. Las muestras se conservaron a $-30{ }^{\circ} \mathrm{C}$ para su posterior análisis mediante PCR. El canino fue tratado al final del estudio con doxiciclina $10 \mathrm{mg} / \mathrm{kg}$ $\mathrm{c} / 12 \mathrm{~h}$ por 21 días.

\section{Descarte de $A$. platys del canino}

Para determinar la posible presencia de $A$. platys antes y después de la infección, se tomó una muestra de sangre con EDTA en un capilar para microhematocrito (tubo wintrobe), el cual se centrifuga a $10000 \mathrm{x} \mathrm{g}$ durante $5 \mathrm{~min}$. Se realiza la prueba de frotis de capa blanca (FCB) buscando las inclusiones con aceite de inmersión a 1000X en 100 campos.

Así mismo, se utilizó la técnica de PCR anidado (Nested Polymerase Chain Reaction) utilizando los iniciadores PLATYS/ EHR16SD. En el primer ciclo se utilizó $47.5 \mu 1$ de buffer para PCR, $47.5 \mu 1$ de $\mathrm{MgCl}_{2}, 9.45 \mu 1$ de dNTPs, $18.9 \mu \mathrm{l}$ del iniciador (1), $18.9 \mu \mathrm{l}$ del iniciador (2), $2.362 \mu 1$ de TAQ polimerasa y $233.85 \mu \mathrm{lde} \mathrm{dH}_{2} \mathrm{O}$. En el segundo ciclo de amplificación se utilizó $47.5 \mu 1$ de buffer para PCR, $47.5 \mu 1$ de $\mathrm{MgCl}_{2}, 9.45 \mu 1$ de dNTPs, $18.9 \mu 1$ del iniciador (1), $18.9 \mu 1$ del iniciador (2), $2.362 \mu 1$ de TAQ polimerasa y $309.45 \mu 1$ de $\mathrm{dH}_{2} \mathrm{O}$. En la programación del termociclador para 40 ciclos se consideró $94{ }^{\circ} \mathrm{C}$ durante 5 min para el precalentamiento, $94^{\circ} \mathrm{C}$ por 1 min para la desnaturalización, $58^{\circ} \mathrm{C}$ durante $1 \mathrm{~min}$ para la unión, $72{ }^{\circ} \mathrm{C}$ durante $1 \mathrm{~min}$ para la extensión y $72{ }^{\circ} \mathrm{C}$ durante 10 min para la extensión final.

\section{Muestras de $R$. sanguineus}

Se extrajeron las glándulas salivales e intestinos de 50 garrapatas sin alimentar (25 hembras y 25 machos) y 30 garrapatas alimentadas de $R$. sanguineus con ayuda de un microscopio estereoscópico (NIKON CLEDS) y una tijera para cirugía ocular. Cada garrapata viva se inmovilizó en agua destilada a $4{ }^{\circ} \mathrm{C}$ en una placa petri. Con pinzas y tijeras oftálmicas se realizó una incisión a través del surco marginal, continuando la incisión por entre los ojos hasta llegar al ángulo escapular, de tal manera que el tegumento dorsal quedó levantado y adherido al cuerpo de la garrapata a la altura de los ángulos escapulares. El extremo libre del tegumento dorsal se abrió con el objeto de dejar expuestos los órganos internos de la garrapata, los cuales se bañaron con solución salina fisiológica, incluyendo las glándulas salivales. El intestino y las glándulas salivales (Figura 2) se lavaron con agua destilada y cuando estuvieron completamente limpios se colocaron en un tubo Eppendorf y se almacenaron a $-30{ }^{\circ} \mathrm{C}$ hasta su procesamiento.

Además, se colectaron 30 ninfas alimentadas del canino con parasitemia, las cuales se procedió a macerarlas para su posterior extracción de $\mathrm{ADN}$.

\section{PCR en Sangre de Caninos y en Garra- patas}

El PCR se realizó en tres pasos: se extrajo el ADN (protocolo de Wizard Genomic DNA purification kit de promega) de la sangre del canino pre y pos-inoculación, de la cepa de $A$. platys inoculada, del macerado de ninfas alimentadas, y del intestino y glándulas salivares de adultos de $R$ sanguineus no alimentadas y alimentadas. El gen $16 \mathrm{~S}$ rRNA de la $A$. platys se amplificó con los cebadores, siguiendo la metodología empleada por Martin et al. (2005). 


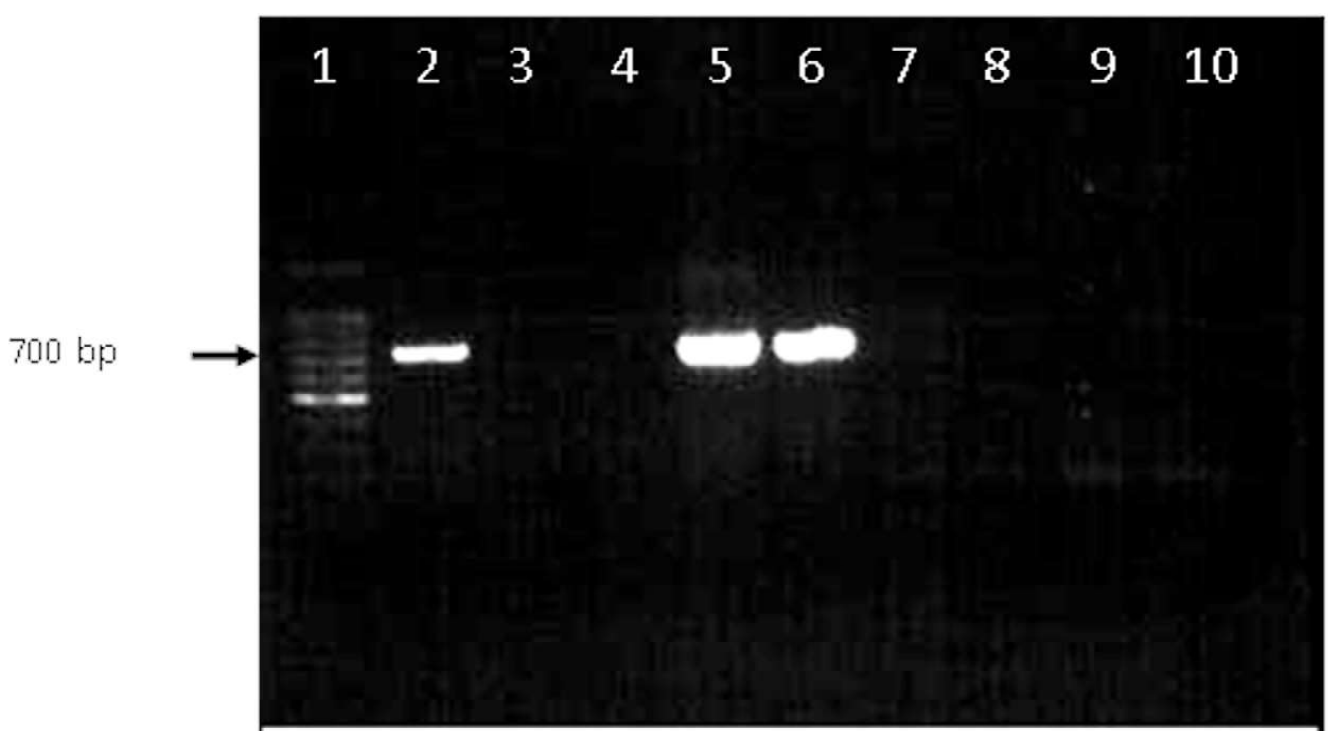

Figura 3. Corrida eletroforética en gel de agarosa. 1: marcador de peso molecular (100-1000); 2: Anaplasma platys (control positivo); 3: control negativo; 4: canino pre-inoculación; 5: A. platys (cepa inoculada); 6: A. platys (canino post-inoculación); 7: macerado de ninfas alimentadas en canino inoculado; 8: intestino de hembras no alimentadas (pos-muda); 9: glándula salival de hembras no alimentadas (pos-muda); 10: intestino de machos no alimentados (post muda).

Primer ciclo: $8 \mathrm{~F}$ (5'-AGTTTGATCATGGTCCAG-3'), 1448R (5-CCATGGCGTG EHR16R (5'-TAGCACTCATCGTTTACAGC-3'), PLATYS (5'GATTTTTGT-CGTAGCTT-GCATTG-3'). Por último, se tomó la fotografía de los productos del PCR purificados en un gel de agarosa $1.5 \%$ con bromuro de etidio expuesto a la luz ultravioleta.

Todo el experimento se realizó siguiendo el cuidado y las consideraciones establecidas en la normativa del Capítulo 3 del Código de Bioética y Bioseguridad para la Utilización de Animales Vivos en Investigación del Fondo Nacional de Ciencia, Tecnología e Innovación (FONACIT, 2008), perteneciente al Ministerio del Poder Popular para Ciencia, Tecnología e Industrias Intermedias.

\section{Resultados}

La corrida electroforética en gel de agarosa al 1.5\% muestra la amplificación de ADN utilizando los cebadores PLATYS/ EHR16SD, los cuales amplifican aproximadamente 678 pares de bases (Figura 3).

Solo en los pozos 5 y 6 se observó una banda similar a la del control positivo, lo que significa que en estas muestras se amplificó un segmento ADN de $A$. platys de 678 pares de bases aproximadamente. En los otros pozos, incluyendo el pozo 4 y el 7 correspondiente a la unidad experimental antes de ser inoculada y al macerado de ninfas luego de ser alimentadas en el canino inoculado no se encontró ADN de A. platys. Asimismo, los 


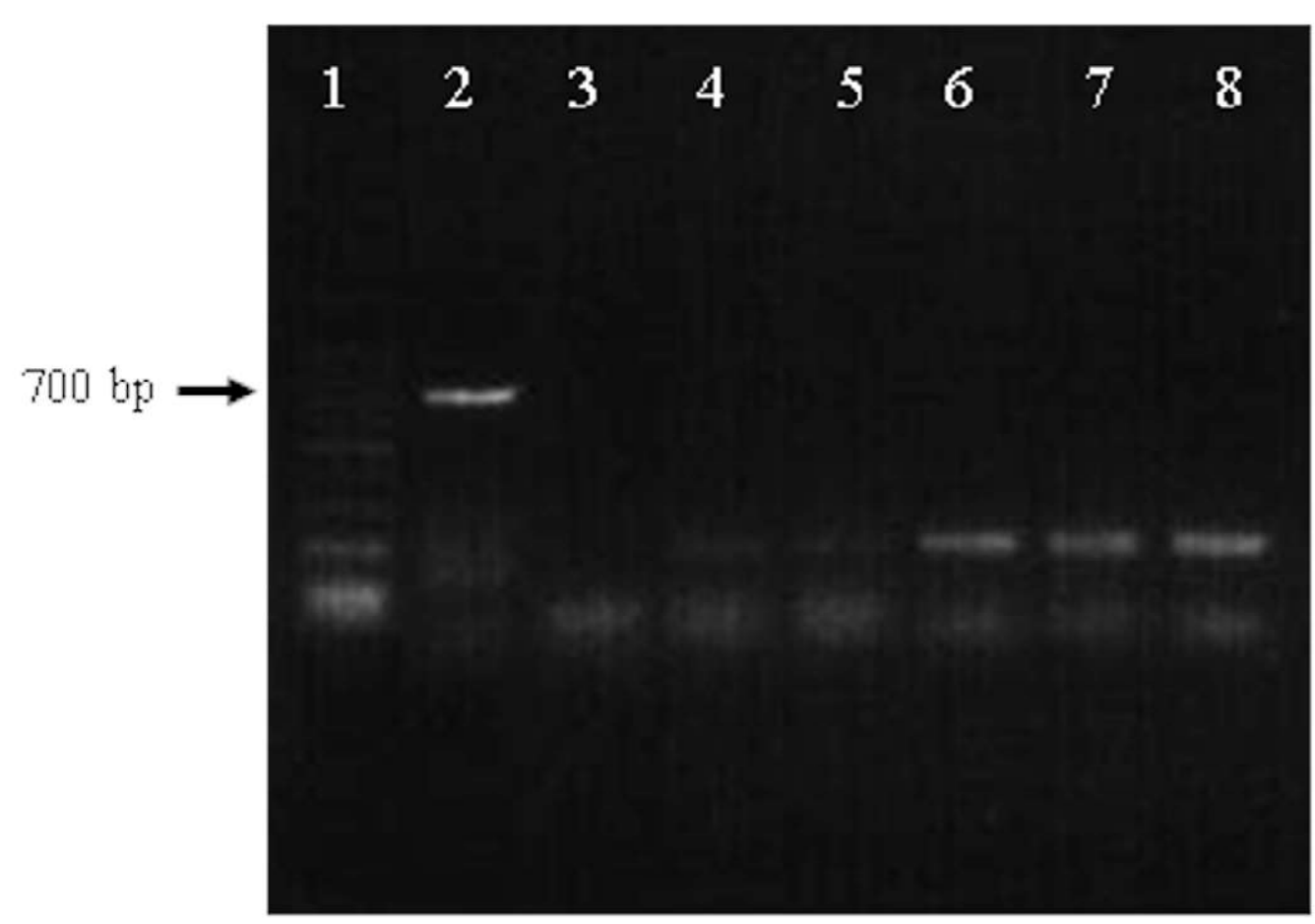

Figura 4. Corrida electroforética en gel: 1: marcador de peso molecular (100-1000); 2: Anaplasma platys (control +); 3: control negativo; 4: glándula salival de machos no alimentados (pos-muda); 5: intestino de hembras alimentadas en canino inoculado; 6: glándula salival de hembras alimentadas en canino inoculado; 7: intestino de machos alimentados en el canino inoculado; 8: glándula salival de machos alimentados en el canino inoculado

pozos 8 al 10 correspondían a los órganos de $R$. sanguineus no alimentados (luego de la muda de ninfa a adultos) resultaron negativos, lo que confirma que no hubo transmisión transestadial.

En la Figura 4 se puede observar la corrida electroforética en gel de agarosa al 1.5\% que muestra la amplificación de ADN utilizando los iniciadores PLATYS/EHR-16SD. No se observaron bandas en ninguno de los pozos de las muestras problema al igual que en el control negativo indicando que no se encontró ADN de A. platys. En el pozo 4 (glándula salival de machos no alimentados [pos-muda de ninfa alimentadas en el canino inoculado]) no se amplificó ADN de $A$. platys, lo cual corrobora que no hubo transmisión transestadial. En forma similar, en los pozos 5 al 8 que corresponden a los adultos alimentados en el canino tampoco se amplificó $\mathrm{ADN}$ de $A$. platys, lo que indica que este último estadio de la garrapata no se llegó a infectar.

\section{Discusión}

Los resultados indican que no se amplificó ADN de $A$. platys en ninfas, adultos no alimentados ni en adultos de $R$. sanguineus alimentados en canino inoculado. Simpson et al. (1991) obtuvieron resultados similares cuando evaluaron a $R$. sanguineus como potencial vector biológico de $A$. platys. Asimismo, Huang et al. (2005) tampoco lograron amplificar ADN de A. platys en tres pool de $R$. sanguineus colectadas en caninos 
PCR positivos, planteando que $R$. sanguineus no es un eficiente transmisor de $A$. platys. Inokuma et al. (2000) no lograron amplificar ADN de $A$. platys en 57 hembras de $R$. sanguineus ingurgitadas, pero lo obtuvieron en tres hembras ingurgitadas de Ixodes ovatus y de una ninfa ingurgitada de Haemaphysalis flava. No obstante estos resultados, Sanogo et al. (2003) trabajando con $R$. sanguineus de perros en África y Latrofa et al. (2016) en Italia lograron amplificar ADN de esta garrapata, lo que indica que $R$. sanguineus podría estar involucrada en la transmisión de la enfermedad en los caninos en esas regiones; sin embargo, esta divergencia en relación a la participación de $R$. sanguineus en la transmisión de $A$. platys puede estar dada por el linaje tropical de esta especie de garrapata en las regiones tropicales y subtropicales (Fantozzi et al., 2018).

Diversos factores pueden influenciar la complacencia de las garrapatas Ixodides para funcionar como vector de enfermedades ricketsiales; entre ellos la especie y género de la garrapata, el sitio de alimentación en el hospedador vertebrado, el tiempo de alimentación, la coordinación de la parasitemia y el momento de alimentación; asimismo, el nivel de parasitemia, el número de garrapatas alimentándose, el estadio de la garrapata, los mecanismos de defensa inmunológicos contra el parásito, tanto del hospedador vertebrado como de la garrapata, y el comportamiento de la garrapata como vector biológico o mecánico (Simpson et al., 1991).

En el presente estudio se proporcionaron condiciones convenientes para que $R$. sanguineus se pudiera alimentar por 5-7 días y se desprendiera naturalmente de las orejas del canino inoculado. Estudios de la bioecología de $R$. sanguineus llevados a cabo en Venezuela revelan que las zonas corporales del huésped vertebrado donde mayormente se localiza este artrópodo es el cuello (31.6\%), seguido de los espacios interdigitales $(24.8 \%)$, las orejas $(19.23 \%)$, y en menor proporción en la cola, base de la cola y las regiones dorsal, ventral y anal (Moissant et al., 1999).

El canino desarrolló la infección por $A$. platys, mostrando signos clínicos a los nueve días de la inoculación, así como mórulas intraplaquetarias a los ocho días de la inoculación, lo cual concuerda con otros reportes (Simpson et al., 1991). La infestación de garrapatas se realizó el día 9 pos-inoculación de la cepa $A$. platys y el canino se mantuvo con parasitemia alta durante el periodo experimental. La mayoría de los factores que pueden influir sobre el vector de enfermedades ricketsiales de $R$. sanguineus fueron cubiertos, por lo que al no amplificarse $\mathrm{ADN}$ de $A$. platys en esta garrapata en su fase de ninfa y adultos, se debe considerar la fase de larvas, el linaje de de $R$. sanguineus, así como otros artrópodos chupadores, como los responsables de la transmisión de A. platys.

\section{Conclusión}

La cepa o linaje de Rhipicephalus sanguineus utilizada en sus fases de ninfas y adulta no participa en la transmisión del Anaplasma platys en el canino.

\section{Literatura Citada}

1. Arraga CM, Parra OC, Palmar M, Chango RE, Alvarado MC. 1997. Ehrlichia platys: preparación del antígeno y uso de la técnica de inmunofluorescencia indirecta (IFI) en caninos y humanos. Rev Cient-Fac Cien Vet 7 : 99-109.

2. Arun A, Reena KK, Rafiqui SI, Jithin MV, Sharma DK, Mahendran K, Garg $\boldsymbol{R}$, et al. 2017. Molecular and parasitological evidence of Anaplasma platys infection in a dog: a case report. Ann Clin Cytol Pathol 3: 1059.

3. Brown GK, Martin AR, Roberts TK, Aitken RJ. 2001. Detection of Ehrlichia platys in dogs in Australia. Aust Vet J 79: 554-558. doi: 10.1111/ j.1751-0813.2001.tb10747.x 
4. Dumler JS, Barbet AF, Bekker CP., Dasch GA, Palmer GH, Ray SC, Rikihisa Y, et al. 2001. Reorganization of genera in the families Rickettsiaceae and Anaplasmataceae in the Order Rickettsiales: unification of some species of Ehrlichia with Anaplasma, Cowdria with Ehrlichia and Ehrlichia with Neorickettsia, description of six new species combinations and designation of Ehrlichia equi and 'HGE agent' as subjective synonyms of Ehrlichia phagocytophila. Int J Syst Evol Micr 51:2145-2165. doi: 10.1099/0020771351-6-2145

5. Fantozzi MC, Linares $M C$, Cuervo PF, Romoli A, Vittaz D, Mera, Sierra R. 2018. Especies de garrapatas (Acari: Ixodidae) parásitas de perros (Canis familiaris) en zonas urbanas del Gran Mendoza, Argentina. FAVE - Sección Ciencias Veterinarias 17: 25-29. doi: https://doi.org/10.14409/ favecv.v17i1.7437

6. [FONACIT] Fondo Nacional de Ciencia, Tecnología e Innovación. 2008. Código de bioética y bioseguridad. $3^{\circ}$ ed. [Internet] Disponible en: http:// www.ciens.ucv.ve:8080/generador/sites/ biolanimlab/archivos/codigo_fonacit_2008.pdf

7. Fossum $T W$. 1999. Cirugía en pequeños animales. Argentina: McGraw Hill. $600 \mathrm{p}$.

8. Harvey JW, Simpson CF, Gaskin JM. 1978. Cyclic thrombocytopenia induced by a rickettsia-like agent in dogs. J Infect Dis 137: 182-188. doi: 10.1093/infdis/ 137.2.182

9. Harrus S, Aroch I, Lavy E, Bark H. 1997. Clinical manifestation of infectious canine cyclic thrombocytopenia. Vet Rec 141:247-250. doi: 10.1136/vr.141.10.247

10. Huang H, Unver A, Perez MJ, Orellana N, Rikihisa Y. 2005. Prevalence and molecular analysis of Anaplasma platys in dogs in Lara, Venezuela. Braz J Microbiol 36: 211-216. doi: 10.1590/S1517-83822005000300002
11. Inokuma H, Raoult D, Brouqui P. 2000. Detection of Ehrlichia platys DNA in brown dog ticks (Rhipicephalus sanguineus) in Okinawa Island, Japan. J Clin Microbiol 11: 4219-4221.

12. Latrofa MS, Dantas-Torres F, de Caprariis D, Cantacessi C, Capelli $G$, Lia RP, Breitschwerdt EB, et al. 2016. Vertical transmission of Anaplasma platys and Leishmania infantum in dogs during the first half of gestation. Parasite Vector 9: 269. doi: 10.1186/s13071-0161545-y

13. Martin RA, Brown KG, Dunstan HR, Timothy KR. 2005. Anaplasma platys: an improved PCR for its detection in dogs. Exp Parasitol 109: 176-180. doi: 10.1016/j.exppara.2004.11.007

14. Moissant E, Vicente M, García Y, Armas S. 1999. Estudio bioecológico de la garrapata del perro, Rhipicephalus sanguineus (Acari: Ixodidae), en un criadero en El Limón (Edo. Aragua), Venezuela. Rev Fac Cs Vet UCV 40: 119-125.

15. Moraes-Filho J, Marcili A, Nieri-Bastos FA, Richtzenhain LJ, Labruna MB. 2011. Genetic analysis of ticks belonging to the Rhipicephalus sanguineus group in Latin America. Acta Trop 117: 51-55. doi: 10.1016/ j.actatropica.2010.09.006

16. Neitz WO, Boughton F, Walters HS, Lange M, Reinecke RK, Walker, Jane $B$, et al. 1971. Laboratory investigations on the life cycle of the karoo paralysis tick (Ixodes rubicundus Neumann, 1904). Onderstepoort J Vet 38: 215-224.

17. Pérez K, Rey-Valeirón C. 2003. Evaluación piloto de Babesia canis (Piroplasmida: Babesidae) y eficacia de garrapaticidas contra Rhipicephalus sanguineus Latreille (Acari: Ixodidae) en el Estado Falcón, Venezuela. Croizatia 4: 49-56.

18. Simpson RM, Gaunt SD, Hair JA, Kocan KM, Henk WG, Casey HW. 1991. Evaluation of Rhipicephalus sanguineus as a potencial biologic vector of Ehrlichia platys. Am J Vet Res 52: 1537-1541. 
19. Sanogo YO, Davoust B, Inokuma HJ, Camicas L, Parola P, Brouqui P. 2003. First evidence of Anaplasma platys in Rhipicephalus sanguineus (Acari: Ixodida) collected from dogs in Africa. Onderstepoort J Vet 70: 205-212.

20. Sartor A. 1994. Aspectos da biologia de Rhipicephalus sanguineus (Latreille, 1806) (Acarina: Ixodidae) em condicoes de laboratorio. Tese de Doctor. Brasil: Univ. Federal Rural do Rio de Janeiro. $80 \mathrm{p}$.
21. Rikihisa Y. 1991. The tribu Ehrlichiae and ehrlichial diseases. Clin Microbiol Rev 7: 286-308.

22. Rikihisa Y. 1996. Rikettsiae and rikettsial diseases. In: Proc V International Symposium on Rickettsiae and Rickettsial Diseases. Stará Lesná, Slovakia.

23. Woody BJ, Hoskins JD. 1991. Ehrlichial disease of dogs. Vet Clin NAmSmall 21: 75-98. doi: 10.1016/S01955616(91)50009-7 